\title{
Ciencia POlítica en Chile: ¿UNA disciplina CONSOLIDADA?*
}

Political Science in Chile: A Consolidated Discipline?

\section{CLAUDIA HEISS}

Instituto de Asuntos Públicos, Universidad de Chile

\begin{abstract}
RESUMEN
Si la ciencia política chilena de comienzos del milenio estuvo marcada por la explosiva oferta de carreras de pregrado, los últimos diez años apuntan a una consolidación que se refleja en proyectos de investigación, publicaciones y la creación de los primeros doctorados disciplinares. Este artículo analiza la oferta de pre y posgrado desde 2005, sus plantas académicas, nivel de publicaciones, proyectos FONDECYT de investigación y los avances de las revistas científicas nacionales.
\end{abstract}

Palabras clave: Ciencia política, investigación, Chile.

\begin{abstract}
If, at the beginning of the Millennium, Chilean political science was characterized by the explosive offer of undergraduate programs, the last ten years show a consolidation of the discipline reflected in research projects, publications and the creation of the first Ph.D. programs in the discipline. This article analyzes the supply of undergraduate and graduate programs since 2005, their academic staffs, level of publication, FONDECYT research projects and the improvements in the national scientific journals.
\end{abstract}

Key words: Political Science, research, Chile.

* Asistente de investigación: Nicolás Matus. Agradezco la generosa ayuda de Alejandro Olivares, Antoine Maillet, Jaime Juica, Arturo Valenzuela y Jonny Heiss. Mi reconocimiento a Patricio Espinoza y Félix Díaz, de CONICYT, por la información sobre proyectos de investigación 
La ciencia política ha experimentado cambios importantes en Chile y América Latina en décadas recientes: el surgimiento de programas de pre y posgrado, la inclusión de revistas académicas en bases de datos estandarizadas, la creación de asociaciones científicas nacionales y de la Asociación Latinoamericana de Ciencia Política, ALACIP, en 2008, la conformación de redes internacionales y grupos de estudio, entre otros. Estos desarrollos han venido de la mano de una creciente autoconsciencia sobre temas como la autonomía disciplinar, agendas de investigación, enfoques metodológicos, campo laboral, publicaciones y formación de las y los politólogos (Altman, 2005; Nolen, 2006; Barrientos, 2013; Buquet, 2013).

La historia de la disciplina en Chile se remonta a los años 50 y 60, cuando un ambiente intelectual excepcional propiciado por la coyuntura política se sumó a la internacionalización propia de la revolución conductista. Más tarde, la transformación de las universidades en un negocio con fines de lucro en los 80 ayudó a la vertiginosa expansión de las carreras de pregrado generando un "boom" de la ciencia política en Chile. El año 2005 se produjo otro "boom": el de la reflexión sobre estos acontecimientos. El número especial de Revista de Ciencia Política ese año marcó un hito, coincidiendo con otros artículos sobre un tema que había estado hasta entonces casi completamente ausente de la bibliografía disciplinar en el país (Altman, 2005; Fuentes y Santana, 2005; Rehren y Fernández, 2005; Fernández, 2005; Navarrete, Morales y Figueroa, 2005).

Estos trabajos daban cuenta del cambio profundo que marcó el surgimiento de la ciencia política como pregrado y su consiguiente masificación. Hasta entonces solo existía un puñado de programas de magíster con fuerte componente interdisciplinario y un reducido grupo de investigadores formados en el extranjero.

Diez años más tarde es posible constatar nuevos desarrollos. Chile avanza hacia una creciente profesionalización, con criterios más transparentes para las contrataciones e información pública sobre plantas docentes y productividad científica.

El número de programas de pregrado se ha estabilizado, ${ }^{1}$ pero tenemos hoy los primeros programas de doctorado en la disciplina. Las plantas académicas de las universidades se han incrementado. Altman (2012: 82) señala que incluso en aquellas universidades latinoamericanas que mantienen criterios "anticuados" para definir la carrera -prestigio, relaciones políticas, antigüedad-, los académicos han comenzado a exigir normas claras y modernas basadas en la producción científica y su impacto; eso está ocurriendo también en el país. Hay más información disponible sobre quiénes conforman los departamentos de ciencia política, aunque en algunas universidades queda aún bastante por avanzar en transparencia. Respecto de la participación de género, las mujeres siguen siendo minoría en docencia e investigación, pero no en los proyectos de jóvenes investigadores, lo que hace prever un futuro más paritario.

Fuentes y Santana (2005) cuentan 11 programas de pregrado. Aquí se consideran 10, aunque con algunos criterios distintos, como excluir la licenciatura en Historia de la Universidad de Valparaíso y las carreras que entregan título de Administrador Público. Los programas nuevos respecto de 2005 son tres: UCT, UAH y USACH. Los que dejan de existir son dos: UTEM y Universidad de las Américas. 
El objetivo de este trabajo es actualizar la reflexión de hace una década y señalar algunos de los desafíos que enfrenta la ciencia política en esta nueva etapa. Para ello, (I) se presentan algunos de los hitos más relevantes en el surgimiento y desarrollo de la disciplina en Chile, (II) se describe la situación actual de los programas de pre y posgrado, (III) sus plantas académicas, (IV) las publicaciones de sus docentes, (V) los proyectos de investigación con financiamiento estatal, especialmente FONDECYT, y (VI) la publicación de revistas académicas nacionales. Por último, se ofrecen algunas conclusiones respecto del estado de consolidación y profesionalización de la ciencia política en el país a la luz de estos datos.

\section{CIENCIA POLÍTICA EN CHILE Y AMÉRICA LATINA}

El contexto político, junto a enfoques y métodos importados principalmente desde Estados Unidos y Europa, han sido los principales determinantes de la agenda de la ciencia política en América Latina. La coincidencia entre política y ciencia política explica el interés por estudiar, en su momento, el quiebre de la democracia, los procesos de democratización, los enclaves autoritarios o la relación entre civiles y militares. Aunque la región ha hecho aportes en estos temas, la ciencia política latinoamericana ha sido también blanco de críticas de parroquialismo, al predominar trabajos históricos y descriptivos de fenómenos locales por sobre estudios comparados (Nolen, 2006).

La ciencia política se desarrolló en Chile en la década del 50 a partir del Derecho Público y Administrativo. En 1954 se crea la Escuela de Ciencias Políticas y Administrativas de la Universidad de Chile, al alero de su Facultad de Ciencias Jurídicas ${ }^{2}$ (Rehren y Fernández, 2005: 41-42; Viacava, 2011: 97). Más tarde la ciencia política se acerca a la sociología, especialmente a partir de las corrientes estructural funcionalista y marxista, para luego perfilarse como disciplina autónoma (Barrientos, 2013; Garretón 2005; Huneeus, 2006). El cambio en la forma de estudiar la política y el interés que genera la revolución conductista por ampliar las fronteras de las investigaciones ayudan a situar a Chile en la escena internacional y surgen los primeros esfuerzos cuantitativos. ${ }^{3}$

Chile tuvo un desarrollo relativamente temprano de la ciencia política al alero de los trabajos realizados en FLACSO y CEPAL en la década del 60. En 1966 se funda el Instituto de Estudios Internacionales de la Universidad de Chile (Huneeus, 2006). Con apoyo del Banco Interamericano de Desarrollo, el mismo año se crea en FLACSO la Escuela Latinoamericana de Ciencia Política y Administración Pública, ELACP, que publica en 1970 la Revista Latinoamericana de Ciencia Política. Aunque enfocados en la economía y la sociología, estos centros desarrollan sin embargo una primera aproximación al estudio de la política como fenómeno independiente. En 1969 se crea el Instituto de Ciencia Política

De allí una vinculación que persiste en la formación de las y los administradores públicos del país.

El desarrollo histórico de la ciencia política es indisociable de las distintas etapas que vivieron las ciencias sociales en Chile respecto de su profesionalización y consolidación. Ver Garretón 2005. 
de la Universidad Católica como una alternativa propiamente politológica a las vertientes de influencia sociológica (Barrientos, 2013: 114; conversación con Arturo Valenzuela).

Aunque existe un difundido argumento de que la democracia es el mejor aliciente al desarrollo de la disciplina, Chile ofrece evidencia ambigua sobre esta relación. Así, Buquet 2013 asocia el exponencial aumento de las publicaciones en ciencias sociales a partir de los 90 al proceso de democratización en América Latina y Huneeus 2006 señala que la Doctrina de Seguridad Nacional culpó a las ciencias sociales de las crisis políticas, justificando intervenir universidades y exiliar académicos.

Sin embargo, aunque las dictaduras militares buscaron obstaculizar la docencia y la investigación en ciencia política, hay evidencia de que no lo lograron en Brasil, México y Colombia (Barrientos, 2013: 116). Chile también parece desafiar la idea de que la democracia es condición necesaria para el desarrollo de la ciencia política (Nohlen, 2006; Huntington, 1992 citado en Barrientos, 2013: 107). El exilio de académicos por las dictaduras de Brasil y Argentina contribuyó al clima intelectual que acompañó al nacimiento de la disciplina en el país, como ocurrió - guardando las proporciones- con los emigrados europeos a Estados Unidos durante la Segunda Guerra Mundial. Más tarde la dictadura promovió, aunque involuntariamente, la cooperación académica a nivel nacional e internacional con miras al retorno a la democracia.

En efecto, tras el golpe militar de 1973 el gobierno cierra la ELACP y, en un esfuerzo por continuar los estudios en la disciplina, se crea la mención en ciencia política de la Licenciatura en Historia de la Universidad Católica de Valparaíso (Barrientos, 2013: 115; Fuentes y Santana, 2005: 18). En 1979 la Universidad Católica comienza a publicar la Revista de Ciencia Política. En 1981 se crea, al alero de la dictadura y con un enfoque geopolítico, el Instituto de Ciencia Política de la Universidad de Chile y en 1982 se inauguran los programas de magíster en ciencia política de la Universidad Católica y Universidad de Chile. En 1983 se funda la Asociación Chilena de Ciencia Política ACCP, que surge como "un espacio de complicidades políticas, muy vinculadas al interés de recuperación de la democracia, más que académicas y profesionales" (Fernández, 2006: 268). Una de las primeras de la región en obtener el reconocimiento de la Asociación Internacional de Ciencia Política, IPSA, entre sus objetivos estaba generar redes para apoyar la recuperación de la democracia (Barrientos, 2013: 119-120; Matus, 2014). Al momento de la transición, la ciencia política aparecía como aún incipiente, pero claramente distinguible de otras ciencias sociales.

A partir de los 90 la disciplina ha avanzado hacia una creciente profesionalización y se ha ampliado considerablemente la oferta académica de pre y posgrado. Del puñado de programas de magíster conformados por docentes con estudios en el extranjero y provenientes de otras disciplinas hemos pasado a una amplia y variada oferta académica

Entre los fundadores, muchos de ellos abogados con formación de posgrado en el extranjero, están: Eduardo Ortiz (su primer presidente), Ricardo Israel, Alberto Van Klaveren, Roberto Durán, Carlos Huneeus, John Mackenzie, Walter Sánchez, Lucía Santa Cruz, Óscar Godoy y Heraldo Muñoz. Poco después se suman Manuel Antonio Garretón, Carlos Portales y Gustavo Lagos, entre otros (Matus, 2014). 
en universidades que son al mismo tiempo los principales polos de la investigación científica, como se verá a continuación.

\section{PROGRAMAS DE PRE Y POSGRADO EN CIENCIA POLÍTICA}

Al año 2015 es posible reconocer programas académicos de universidades chilenas en ciencia política en tres niveles: (a) de pregrado, los que pueden culminar ya sea en una licenciatura o un título profesional, (b) de magíster y (c) de doctorado.

Estos programas exhiben una importante diversidad en su dependencia institucional: se alojan en institutos o facultades de ciencias sociales, humanidades, historia o gobierno. Tal situación da cuenta de su origen interdisciplinario y los hace más vulnerables a cuestionamientos respecto de su arraigo disciplinario y consolidación como ámbito autónomo de estudio. Adicionalmente, el hecho de que el pregrado en Chile se entienda mayoritariamente como conducente a un título profesional y no a una licenciatura o grado de bachiller genera expectativas de formación diferentes del modelo generalista que exhibe la mayor parte de los países desarrollados.

Los sitios web de los programas académicos de ciencia política coinciden en señalar a la Teoría Política, la Política Comparada y las Relaciones Internacionales como las principales subáreas de la disciplina. A veces se incluyen también Metodología o Defensa como temas de especialización. Seguimos aquí el precedente de Altman 2012, Fuentes y Santana 2005 y otros de incluir las relaciones internacionales como parte de la disciplina. Esto se justifica además porque reconocidos politólogos e incluso fundadores de la Asociación Chilena de Ciencia Política trabajan en centros de relaciones internacionales. No ocurre lo mismo con el mundo de la teoría política, más desperdigado en subunidades de facultades de filosofía, programas de historia de las ideas o de humanidades.

\section{Pregrado}

Al año 2015 existen diez programas de pregrado en ciencia política en Chile. La mayor parte de ellos tiene una duración de diez semestres. ${ }^{5}$ Tres son de ocho semestres: UDP, ARCIS y UGM. De acuerdo con la información disponible en sus sitios web y los de agencias acreditadoras, la mitad de esos programas han sido acreditados por agencias oficiales: PUC y UDP por siete años, UCT y UAH por cinco y UCEN por cuatro. ${ }^{6}$

Este listado no considera seis carreras adicionales que llevan el nombre de "ciencia política", pero que entregan título profesional de Administrador Público, como ocurre con las universidades de Chile, de Los Lagos, Miguel de Cervantes, de Concepción, de

5 La duración está determinada por una norma del sector público chileno que exige carreras profesionales de diez semestres para poder desempeñarse como profesional en el aparato estatal.

6 La acreditación es una certificación de calidad a la que se someten voluntariamente los programas académicos y universidades chilenas para poder acceder a financiamiento estatal. Solo en los casos de medicina y pedagogía es obligatoria. Las acreditaciones pueden ir desde uno a siete años (mifuturo.cl, sitio web del Ministerio de Educación). 
Talca sede Santiago y San Sebastián sede Concepción. Tampoco considera la mención en Ciencia Política de la Licenciatura en Historia de la U. Católica de Valparaíso. Es importante tener en cuenta que algunos de los investigadores que acceden a fondos concursables de investigación en ciencia política, especialmente FONDECYT, pertenecen a estas y otras carreras afines.

Si se compara la Tabla 1 con la información en Fuentes y Santana 2005, vemos que se han añadido tres carreras de pregrado: USACH y UAH en 2007 y UCT en 2008 mientras que han desaparecido dos, las de UTEM y Universidad de las Américas. No hay, por lo tanto, una variación importante en la oferta de pregrado durante los últimos diez años, comparable al vertiginoso boom que se produjo en la década anterior.

\section{Magíster}

En Chile existen tres programas de Magíster en Ciencia Política: los de la PUC, Universidad de Chile y UTEM. También tienen un fuerte componente disciplinar, ya sea por depender de escuelas de ciencia política o por sus contenidos, los de la UDP (Política y Gobierno), ANEPE (Ciencia política, seguridad y defensa), Universidad Mayor (Ciencia política y comunicación) y Universidad de Concepción (Política y Gobierno). Eso deja en siete los programas propiamente disciplinares. Si se añaden los magísteres en relaciones internacionales del I.E.I. de la Universidad de Chile, la USACH y la PUCV, todos ellos con una importante presencia de politólogos entre sus docentes, quedan en 10 los programas de magíster de ciencia política en el país (Tabla 2). Si se considera el conjunto de magísteres en las áreas de ciencia política, relaciones internacionales, administración y gerencia pública, y políticas públicas, el total de programas asciende a 23. La mayoría de ellos es vespertino y dura dos años.

\section{Doctorado}

El cambio más relevante a nivel de posgrado en la última década es el surgimiento de los primeros doctorados en la disciplina: los de la PUC (2007) y UDP (2014). También es relevante la creación del Magíster en Política y Gobierno de la UDP el 2013, que apunta al fortalecimiento de la disciplina en todos los niveles en esa universidad.

La PUC ha lanzado ya al mercado a los primeros doctores formados en el país, lo que plantea interesantes interrogantes respecto de su inserción laboral en general y en comparación con la de académicos con doctorados extranjeros. Hasta la reciente oferta de estos nuevos doctorados, los académicos chilenos se formaban en el extranjero o en programas afines como el doctorado en Ciencias Sociales de la Universidad de Chile, en Procesos Sociales y Políticos en América Latina de ARCIS o el de Estudios Americanos de USACH. Los nuevos doctorados disciplinares constituyen un cambio fundamental en el escenario académico y un avance significativo hacia la consolidación de la disciplina en el país. 


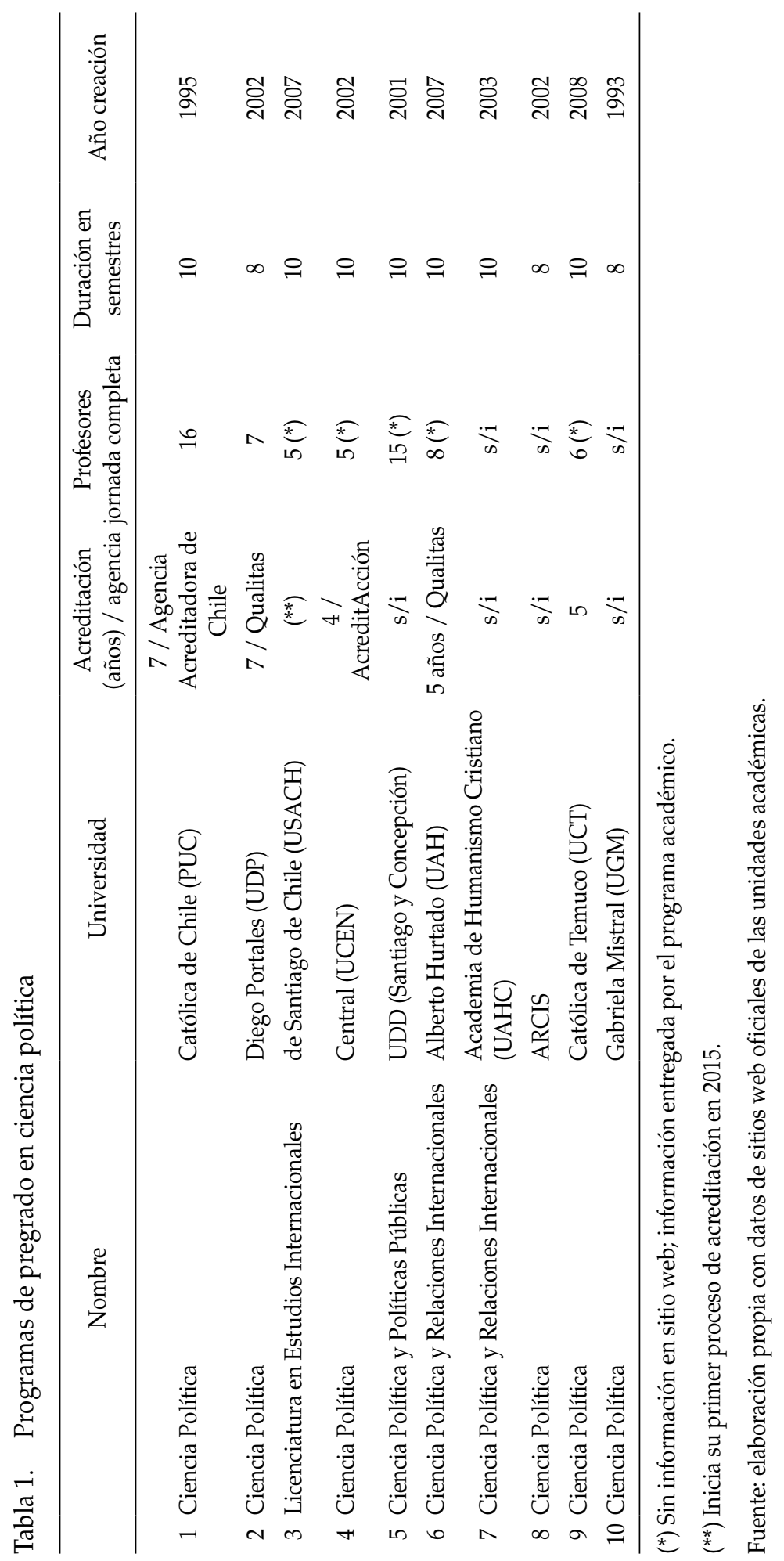




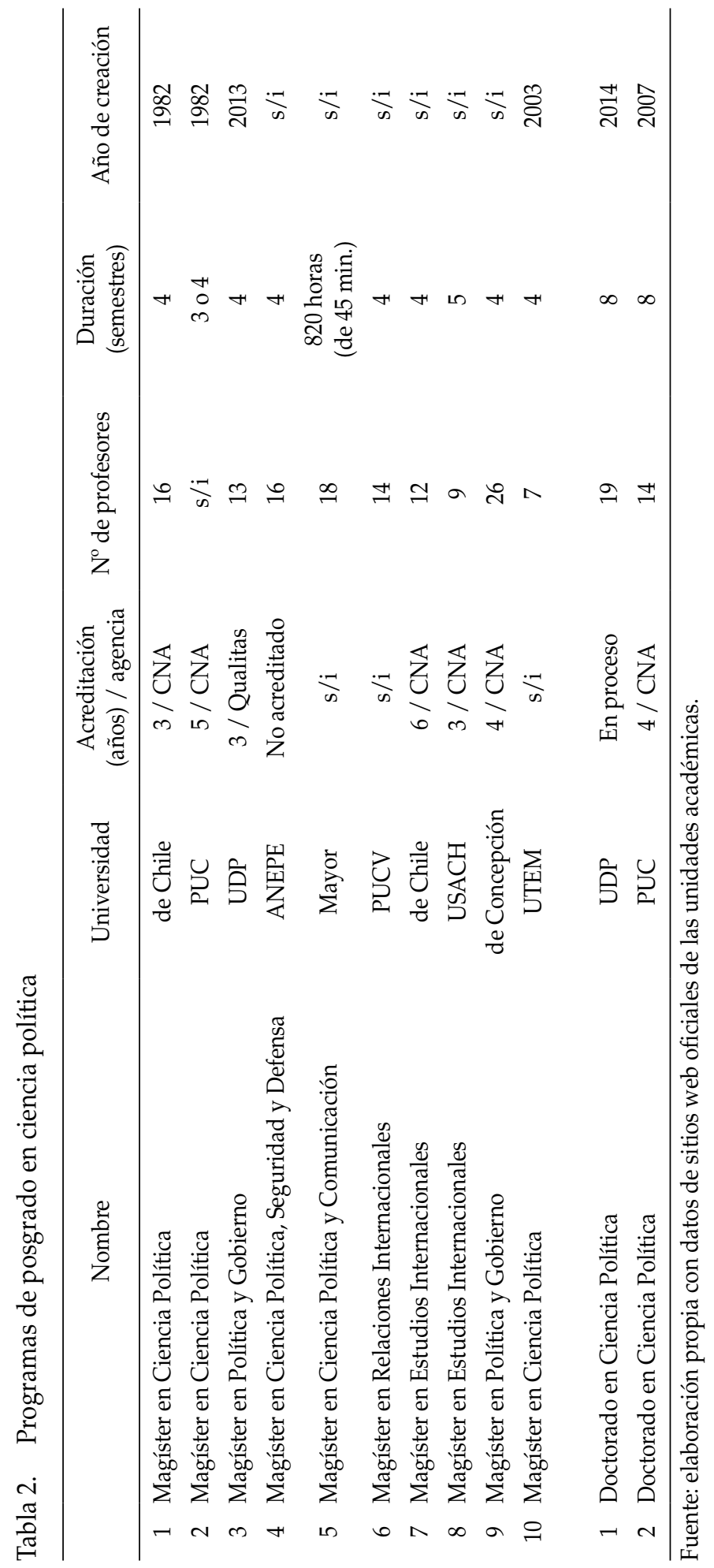




\section{PLANTAS ACADÉMICAS}

Las diversas modalidades de contratación, dedicación en horas y tareas desempeñadas dificultan establecer un criterio claro sobre quiénes forman parte de un departamento de ciencia política (Altman, 2012: 73). Los contratos pueden ser indefinidos o temporales y renovables, por jornada completa (44 horas semanales) o por jornadas parciales; los convenios a honorarios pueden abarcar un rango amplio de jornadas de trabajo, desde unas pocas horas a una importante carga administrativa o docente. Por último, hay académicos que se dedican principal o exclusivamente a la docencia, investigación o administración, mientras otros combinan dos o todas estas tareas. Salvo en contadas excepciones, la carrera académica en Chile sigue siendo precaria (Fernández, 2006: 270). Profesores considerados "de planta" suelen estar sujetos a renovaciones periódicas de sus contratos y la negociación caso a caso prima sobre criterios objetivos para fijar promociones, salarios, sabáticos, etcétera.

Podría decirse, usando un criterio laxo, que pertenecen a un departamento de ciencia política quienes "tienen oficina" en la universidad y no pertenecen a otra unidad académica. Solo los sitios web de las carreras de pregrado de ciencia política de PUC y UDP entregan información detallada respecto de este punto: PUC tiene 16 académicos jornada completa, UDP 7 (Tabla 1).

Especialmente en departamentos con una mayoría de profesores externos, quienes están contratados a jornada completa suelen tener cargos administrativos. De ellos debería esperarse, además, publicaciones y proyectos de investigación. Todos los programas tienen, además de sus profesores "de planta", otros dos tipos de docentes: profesores contratados por jornada parcial para impartir docencia, y profesores de planta de la universidad, pero pertenecientes a otras unidades académicas. Al revisar el listado de profesores se hace patente que aquellos programas que descansan en mayor medida en profesores externos suelen repetir nombres. Algunos profesores hacen clases en tres o más universidades distintas.

Un análisis del listado completo de profesores que figuran en los sitios web de los programas de pre y posgrado en ciencia política analizados aquí muestra que las mujeres siguen siendo una minoría, con poca variación respecto de los datos señalados por Fuentes y Santana 2005, que situaban en 24,5\% el promedio de académicas. Según nuestro cálculo, las mujeres constituyen al 2015 solo el $23 \%$ llegando a niveles tan bajos como el $6 \%$ en UCT y $8 \%$ en UGM, que cuentan con solo una académica cada una. En la mayor parte de los programas, el cuerpo académico está conformado por alrededor de un tercio de mujeres (Tabla 3). Esta realidad contrasta con la composición de los estudiantes, que tiende a ser paritaria. ${ }^{7}$

$7 \quad$ Fernández (2006: 265) observaba una virtual paridad entre estudiantes de pregrado y una leve prevalencia masculina en los magíster en ciencia política de Universidad de Chile y PUC. 
Tabla 3. Académicos por programa según género

\begin{tabular}{lccc}
\hline \multicolumn{1}{c}{ Universidad } & Hombres & Mujeres & \% Mujeres \\
\hline PUC & 24 & 10 & 29 \\
UDP & 10 & 4 & 29 \\
UCEN & 33 & 13 & 28 \\
UDD Santiago & 23 & 11 & 32 \\
UDD Concepción & 15 & 6 & 29 \\
UAH & 5 & 2 & 29 \\
ARCIS & 26 & 10 & 28 \\
UAHC & 15 & 2 & 12 \\
UCT & 11 & 1 & 8 \\
UGM & 16 & 1 & 6 \\
Universidad de Chile INAP & 4 & 2 & 33 \\
Universidad de Chile IEI & 10 & 2 & 17 \\
USACH & s/i & s/i & s/i \\
\hline
\end{tabular}

Fuente: elaboración propia con datos de sitios web oficiales de las unidades académicas.

\section{IV. ¿PUBLICAR O PERECER?}

Los deberes académicos suelen incluir docencia, administración, extensión e investigación. De todos ellos, el último es el que determina la capacidad de crear nuevo conocimiento y se mide por medio de las publicaciones. A su vez, publicar en plataformas de prestigio, como las revistas indexadas o libros con referato, determina la capacidad de incidir en la disciplina más allá de debates locales. Pero ¿qué relevancia dan a esta dimensión las escuelas y departamentos de ciencia política del país?

En su trabajo sobre productividad académica de los departamentos de ciencia política de la región, Altman (2012: 77-79) señala que existe variación respecto de criterios institucionales sobre el peso de la investigación en el ascenso en la carrera académica y el pago de incentivos por tipo de publicación. Lo mismo puede decirse de las universidades chilenas. Si en algunos casos las publicaciones son vitales, en otros publicar sigue teniendo pocas repercusiones profesionales y salariales. Sin embargo, esta última realidad, que Altman atribuye a las universidades públicas de Argentina y Uruguay, se ve crecientemente desafiada en Chile por las presiones de la acreditación universitaria y es probable que la reforma educacional en curso contribuya a incrementar aún más las exigencias de publicar, y de hacerlo en plataformas con estándares exigentes.

Este desarrollo es positivo en cuanto refuerza la función de creación de conocimiento científico de las universidades, que ha sido débil en la institucionalidad educacional desregulada que acompañó al crecimiento de la oferta de carreras de pregrado, incluida la ciencia política, con modelos de financiamiento basados en los aranceles de los estudiantes. Al mismo tiempo, promueve criterios objetivos de medición, como la indexación de 
las revistas y su factor de impacto. ${ }^{8}$ Lo negativo, por otro lado, es que genera un sesgo hacia cierto tipo de investigaciones. El énfasis en indicadores rígidos desincentiva la publicación en revistas de "nicho", que pueden tener influencia en círculos relevantes pero reducidos, y en libros u otros formatos de menor difusión académica pero mayor impacto en la sociedad.

Mientras Buquet (2013) señala que existe una tendencia de las y los cientistas sociales de América Latina a publicar en revistas de su propio país, Altman identifica una fuerte correlación entre la formación de doctorado que recibieron las y los académicos en países desarrollados, especialmente Estados Unidos, y la tasa e impacto de las publicaciones. (Altman, 2012: 80).

Freidenberg y Malamud (2013) describen a los "expatriados" del Cono Sur como un significativo factor de incidencia. Señalan que especialmente las y los cientistas políticos de Argentina y Uruguay han ayudado a dar visibilidad a la ciencia política de la región mediante sus publicaciones. El aporte de Chile en este sentido es casi nulo. Los autores identifican 81 académicos de la ciencia política del Cono Sur de generaciones posdictadura, la mayor parte con especialidad en política comparada, trabajando en el extranjero: 62 argentinos, 10 brasileños, 8 uruguayos y solo un chileno. ${ }^{9}$ En cambio, el Instituto de Ciencia Política de la PUC, en Santiago, figura como uno de los centros receptores de la diáspora de politólogos de la región (Freidenberg y Malamud, 2012: 4).

El financiamiento local de los estudios de posgrado en el extranjero es determinante en que los brasileños regresen a su país, mientras que los argentinos y uruguayos suelen recibir financiamiento de la institución receptora. Esto plantea dudas, para el caso chileno, de que el requerimiento de Becas Chile de regresar al país sea la mejor forma de desarrollar la disciplina, al reducir la posibilidad de una diáspora chilena de politólogos. Los autores señalan que más que "fuga de cerebros" las diásporas han mostrado ser tanto o más productivas que la exigencia de regresar a casa, al aportar redes internacionales y académicos en posiciones de poder que mantienen lazos con su país (Freidenberg y Malamud, 2012: 12).

Más allá de la incidencia, quisimos ver el peso que asignan a investigación las unidades académicas del país. Sopesar adecuadamente las publicaciones recientes en ciencia política requiere considerar el contexto de aumento generalizado de los artículos indexados en las ciencias sociales de América Latina. Buquet (2013) muestra que el número de publicaciones de académicos afiliados a universidades de la región en revistas de ciencias sociales que pertenecen a Scopus -la base de datos de mayor cobertura mundial- ha aumentado en forma exponencial desde 1990, y especialmente a partir de $2005 .{ }^{10}$

8 La indexación supone el cumplimiento de requisitos formales como referato doble ciego, periodicidad, etc., mientras que el factor de impacto refleja cuán citada es la publicación por otras fuentes académicas.

9 Tres años después sabemos que el chileno mencionado en ese artículo se encuentra de regreso en el país.

10 El aumento de publicaciones de latinoamericanos en el índice Scopus se debe a mayores exigencias hacia los investigadores de publicar en revistas indexadas, pero también a la creciente incorporación a esa base de datos de revistas que se publican en América Latina (Buquet, 2013). 
Para conocer el nivel de publicaciones de las y los académicos chilenos se construyó una base de datos a partir de sus perfiles en los sitios web de los programas de pre y posgrado incluidos en las Tablas 1 y 2. Esta información ofrece una idea general sobre el papel que juega la investigación en la respectiva institución, aunque ciertamente se trata de un indicador impreciso al depender del nivel de actualización del sitio web. Aún así, parece relevante ver si las universidades dan importancia a mostrarse como centros de creación de conocimiento por medio de sus portales.

A diferencia de Altman (2012), destacamos aquí el volumen total de publicaciones informadas, independiente de su nivel de impacto. Es necesario advertir que este indicador seguramente subestima la producción académica más reciente (2014 y 2015) por falta de actualización. Asimismo, no es sensible a la calidad de la publicación. Se podría suponer que las publicaciones de mayor impacto han requerido una mayor inversión de tiempo, por lo que no sería correcto inferir que se investiga más o menos meramente a partir del número de publicaciones.

A pesar de estas dificultades, una mirada al volumen de publicaciones reportado por los sitios web de programas de ciencia política ofrece luces sobre la relevancia que las universidades y departamentos respectivos asignan a esta parte del trabajo de sus académicas y académicos.

Las publicaciones informadas para el periodo 2010-2014, incluyendo los textos anunciados para 2015, son 269. Esto incluye libros, capítulos de libros y artículos de revistas académicas. De ese total, más de la mitad (142) son artículos y casi un tercio (78) capítulos de libro. Luego figuran los libros (42), reseñas (3) y otros (4).

Las universidades que reportan más publicaciones son UDP (111) y PUC (68), seguidas por los institutos de la Universidad de Chile INAP (36) e IEI (14). Entre los 142 artículos reportados por los sitios web, la mayoría (89) corresponde a publicaciones ISI. Las instituciones que publican más artículos ISI en el periodo son PUC (36) y UDP (34), seguidas a bastante distancia por UDD (9), U. de Chile (9 entre INAP e IEI) y UAH (4).

Entre 2010 y 2013, el número de artículos ISI publicados anualmente varía entre 17 y 20. La baja a 11 en 2014 probablemente sea atribuible, en parte al menos, a la falta de actualización de la información en línea. Sería interesante poder establecer, de acuerdo con la planta académica y el número e impacto de publicaciones, la productividad de los profesores de las diversas unidades. Hemos dejado fuera este cálculo porque las plantas docentes de pregrado, para las que tenemos información sobre contrataciones de jornada completa, no incluyen a profesores de posgrado o de institutos de investigación que podrían concentrar un porcentaje importante de las publicaciones. Con todo, cabe señalar que las instituciones que más publican son PUC y UDP. La primera concentra la mayor cantidad de artículos ISI, mientras que la segunda supera a todas las instituciones en volumen de publicaciones, a pesar de una planta relativamente pequeña de contrataciones de jornada completa. 
Tabla 4. Publicaciones 2010-2015 por institución

\begin{tabular}{lcc}
\hline & Publicaciones & Artículos ISI \\
\hline PUC & 68 & 36 \\
UDP & 111 & 34 \\
UDD & 11 & 9 \\
UCEN & 4 & 0 \\
UAH & 22 & 4 \\
Universidad de Chile INAP & 36 & 3 \\
Universidad de Chile IEI & 14 & 3 \\
USACH & 3 & 0 \\
Total & 269 & 89 \\
\hline
\end{tabular}

(*) Las instituciones no mencionadas no informan publicaciones en sus sitios web.

Fuente: elaboración propia con datos de sitios web oficiales de las unidades académicas.

\section{FONDOS DE INVESTIGACIÓN}

La principal fuente de financiamiento de proyectos de investigación en ciencia política en Chile es estatal y proviene de la Comisión Nacional de Investigación Científica y Tecnológica, CONICYT, creada en 1967 y dependiente del Ministerio de Educación. Esta entidad administra el Fondo Nacional de Desarrollo Científico y Tecnológico, FONDECYT, principal fuente de financiamiento de proyectos individuales de investigación en el país.

Existen fondos más generosos que los asignados por FONDECYT, como los Fondos de Areas Prioritarias (FONDAP) y Programas de Investigación Asociativa (Anillos) de CONICYT, y la Iniciativa Científica Milenio del Ministerio de Economía. Estos suelen involucrar distintas áreas disciplinares y varios centros de investigación nacionales y extranjeros.

A modo de ejemplo, y aunque se trata de centros interdisciplinarios e interinstitucionales, entre los FONDAP se pueden considerar relevantes para la creación de conocimiento politológico el Centro Interdisciplinario de Estudios Interculturales e Indígenas (ICIIS) y el Centro de Estudios del Conflicto y la Cohesión Social (COES). Entre los proyectos Anillos de la disciplina está el proyecto Relaciones transfronterizas entre Bolivia y Chile: Paradiplomacia y prácticas sociales 1904-2004 (Universidad Arturo Prat). Importantes núcleos Mileno formados en años recientes en ciencia política son los de Estatalidad y Democracia en América Latina (PUC) y Desafíos a la Representación (UDP). Por su volumen numérico, sin embargo, analizar los proyectos FONDECYT adjudicados en los últimos años parece lo más apropiado para formarse una idea del panorama de la investigación en la disciplina.

Anualmente FONDECYT abre tres concursos: Regulares (PFR), de Iniciación en Investigación (PFI) y de posdoctorado. Los PFR están orientados a investigadores con trayectoria y pueden incluir, además del investigador responsable, a coinvestigadores 
y sus instituciones patrocinantes, de pre y posgrado. Duran entre dos y cuatro años. A partir de 2006 se crearon los PFI para investigadores que hayan obtenido el grado de doctor en los últimos cinco años, los que tenían dificultades para acceder a los PFR por la valoración que estos atribuyen a las publicaciones anteriores y, especialmente, a la obtención de otros proyectos FONDECYT. En este caso no se permiten coinvestigadores y la duración es de dos a tres años. Los PFI solo pueden ser entregados una vez. Por último, los proyectos de posdoctorado están orientados a investigadores que hayan obtenido el grado de doctor en los últimos tres años y duran dos a tres años. Los montos son considerablemente menores que los antes descritos (conicyt.cl). ${ }^{11}$

Los proyectos que postulan a FONDECYT Regulares, de Iniciación y de posdoctorado son evaluados por 25 grupos de estudios, los que representan distintas áreas del conocimiento. Los proyectos de la disciplina se enmarcan en el grupo "Ciencias jurídicas, estudios internacionales y ciencia política". Este grupo abarca 16 subáreas, incluidos ciencia política, estudios internacionales y cooperación internacional, criminología y otras 13 áreas del Derecho. En este trabajo, y de acuerdo con las definiciones disciplinares planteadas más atrás, se consideran como parte de la disciplina las dos primeras subáreas: ciencia política y estudios internacionales y cooperación internacional.

En estas dos categorías, desde 2005 han postulado un total de ocho proyectos de posdoctorado y se han adjudicado solo dos. Respecto de los proyectos de cooperación internacional hay cuatro aprobados en el periodo: uno por año entre 2005 y 2008. En consecuencia, el grueso de los fondos de investigación individuales y donde es posible observar tendencias se encuentra en los PFR y PFI, que se analizan con más detalle.

Las cifras muestran una correlación entre los PFR postulados y los adjudicados en la disciplina, pero entre 2005 y 2010 ella no es proporcional. En ese periodo, a pesar de una variación del orden de $60 \%$ en las postulaciones, la adjudicación se mantiene constante en cuatro o cinco proyectos. El 2010 se produce una llamativa baja tanto en proyectos regulares postulados como en adjudicados (solo uno) y posteriormente se evidencia una correlación más estrecha entre el volumen de proyectos concursados y los adjudicados en la disciplina. O sea, mientras más proyectos de la disciplina postulan, más logran el financiamiento.

Si bien la curva de proyectos regulares postulados muestra importantes variaciones de un año a otro, la línea de tendencia (o ajuste promedio) es prácticamente horizontal, lo que implica que no existe una tendencia al alza del número de PFR postulados. Los PFI también han tenido importante variación, pero hay una clara tendencia al alza tanto en los proyectos concursados como en los adjudicados a partir del año 2009 (Gráfico 2). Estos números contradicen una extendida visión de que se hace cada vez más difícil obtener PFR porque ha habido un incremento exponencial en las postulaciones. Esa percepción sí parece, en cambio, válida respecto de los PFI.

11 El programa de Incentivo a la Cooperación Internacional, que estaba disponible como fondo individual a comienzos del periodo aquí analizado, ha sido reorientado a la configuración de redes internacionales entre centros de investigación, por lo que ya no está radicado en FONDECYT. 
Gráfico 1. PFR en ciencia política postulados y adjudicados

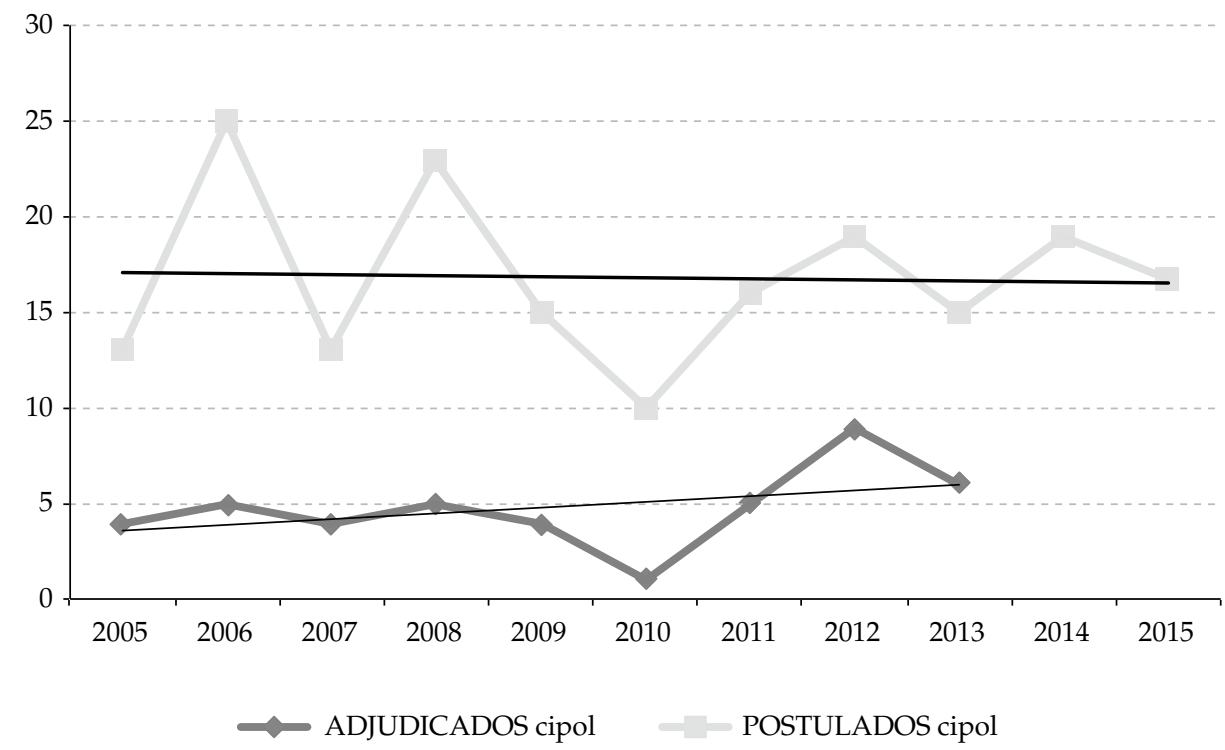

Gráfico 2. PFI en ciencia política postulados y adjudicados

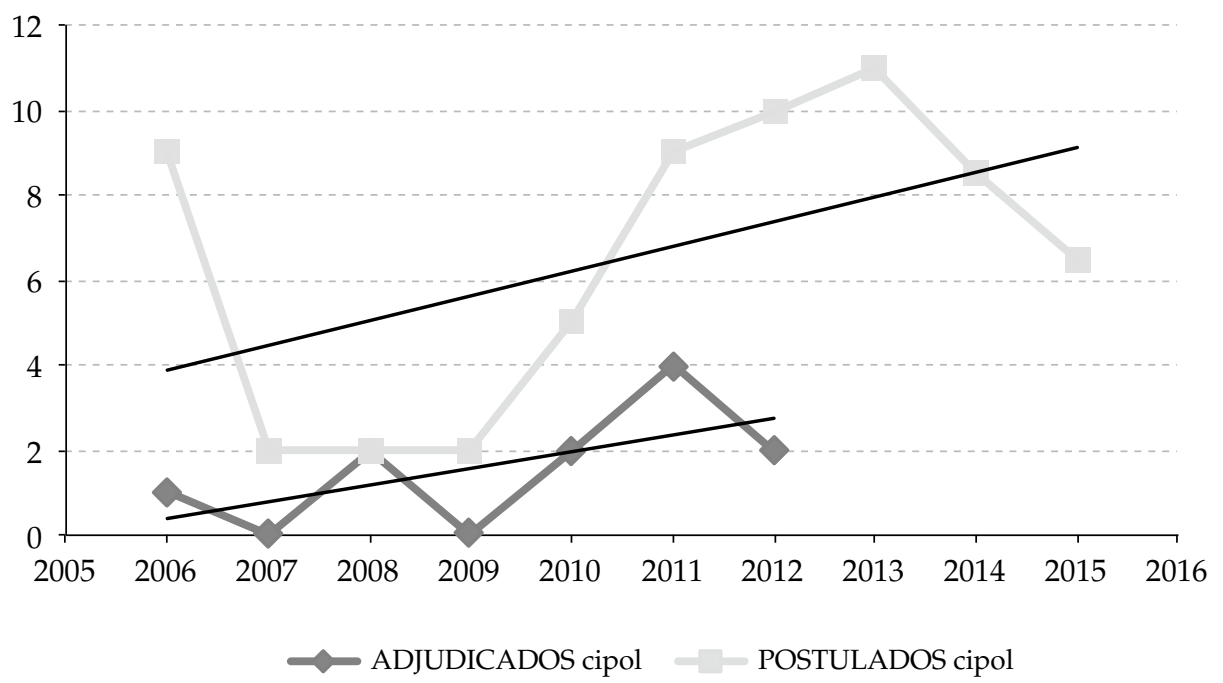

Un debate frecuente entre los académicos de la disciplina es la conveniencia o no de pertenecer al grupo de ciencias jurídicas en lugar de constituir un grupo propio, donde los proyectos de ciencia política únicamente compitan entre sí. Las conclusiones sobre este punto no son concluyentes. Si ciencia política se independizara de ciencias jurídicas, sabemos que los montos totales serían sustantivamente menores. No competiríamos con otras áreas, pero no sabemos exactamente cuál sería el resultado de competir entre 
nosotros. Lo que sí sabemos es que, en la actualidad, ciencia política contribuye un poco más que el resto del grupo a la presentación de proyectos y se adjudica un poco menos que el promedio del grupo.

Los montos a asignar para cada grupo se determinan según el volumen general de proyectos postulados el año anterior. Mientras más proyectos postulen, mayores serán los recursos asignados al grupo. El Gráfico 3 muestra la tasa de éxito (o adjudicación) de los proyectos de ciencia política y estudios internacionales en comparación con la tasa de éxito del grupo de ciencias jurídicas. Salvo la anomalía del año 2010, donde se presentaron 10 PFR de la disciplina, pero solo uno fue adjudicado, se observa que casi todos los años las y los cientistas políticos se adjudican alrededor de un 10\% menos de proyectos que el promedio del grupo. Cabe señalar que a partir de 2011 se observa un incremento de los proyectos adjudicados tanto de la disciplina como del grupo respecto de todos los años anteriores desde 2005.

El Gráfico 4 muestra la contribución de la disciplina al número total de proyectos postulados al grupo de ciencias jurídicas y la participación de ciencia política en el total de proyectos adjudicados al grupo. Este dato es relevante porque, como se ha señalado, el volumen de recursos asignados por FONDECYT a cada uno de los grupos de investigación se determina en función del número de postulaciones, independiente de la probabilidad de éxito que ellas tengan. Se han agregado en el gráfico las líneas de tendencia de estas dos curvas. Ellas muestran que la participación de ciencia política en las postulaciones se mantiene casi constante (presenta un leve aumento del 1\% en promedio), mientras que la participación de ciencia política en las adjudicaciones presenta una disminución de alrededor del 8\% (de 33\% a 25\%). Así, si bien ciencia política aportó el 2013 el 30,6\% de los proyectos FONDECYT Regulares postulados en el grupo, solo constituye el 26,1\% de los proyectos adjudicados.

Gráfico 3. Tasa de éxito. Porcentaje de adjudicación de PFR de ciencia política vs. grupo CJ

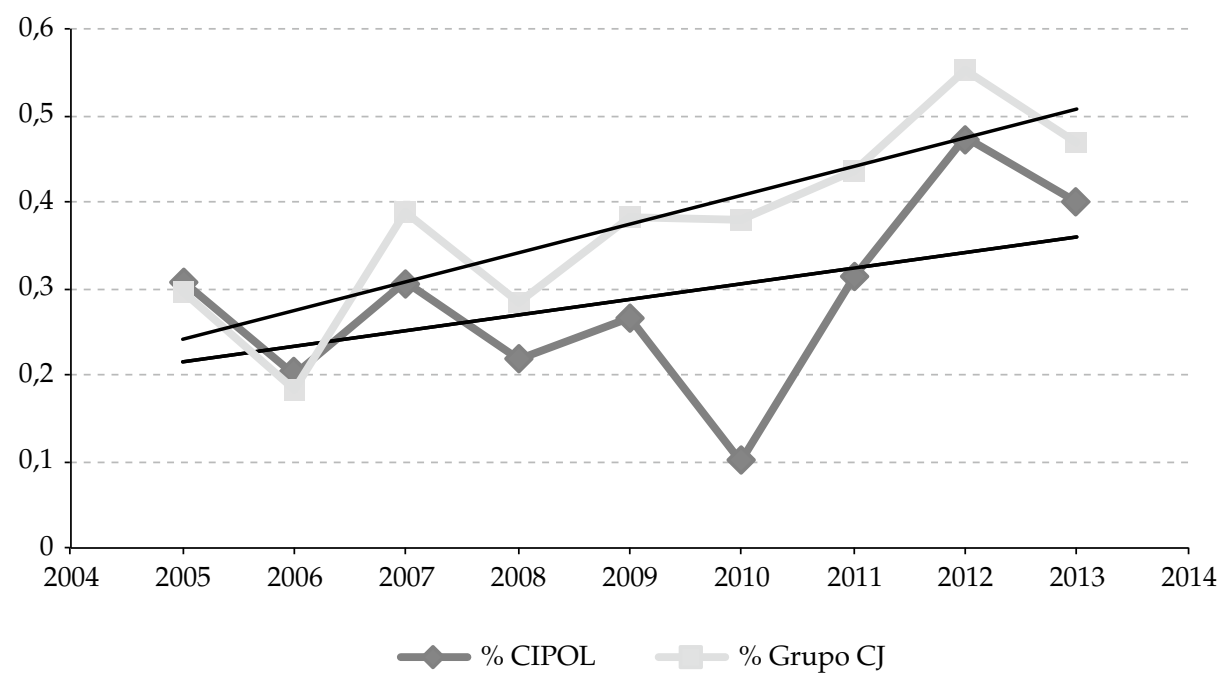


Gráfico 4. Participación de ciencia política en el grupo CJ: tasas de postulación y de adjudicación.

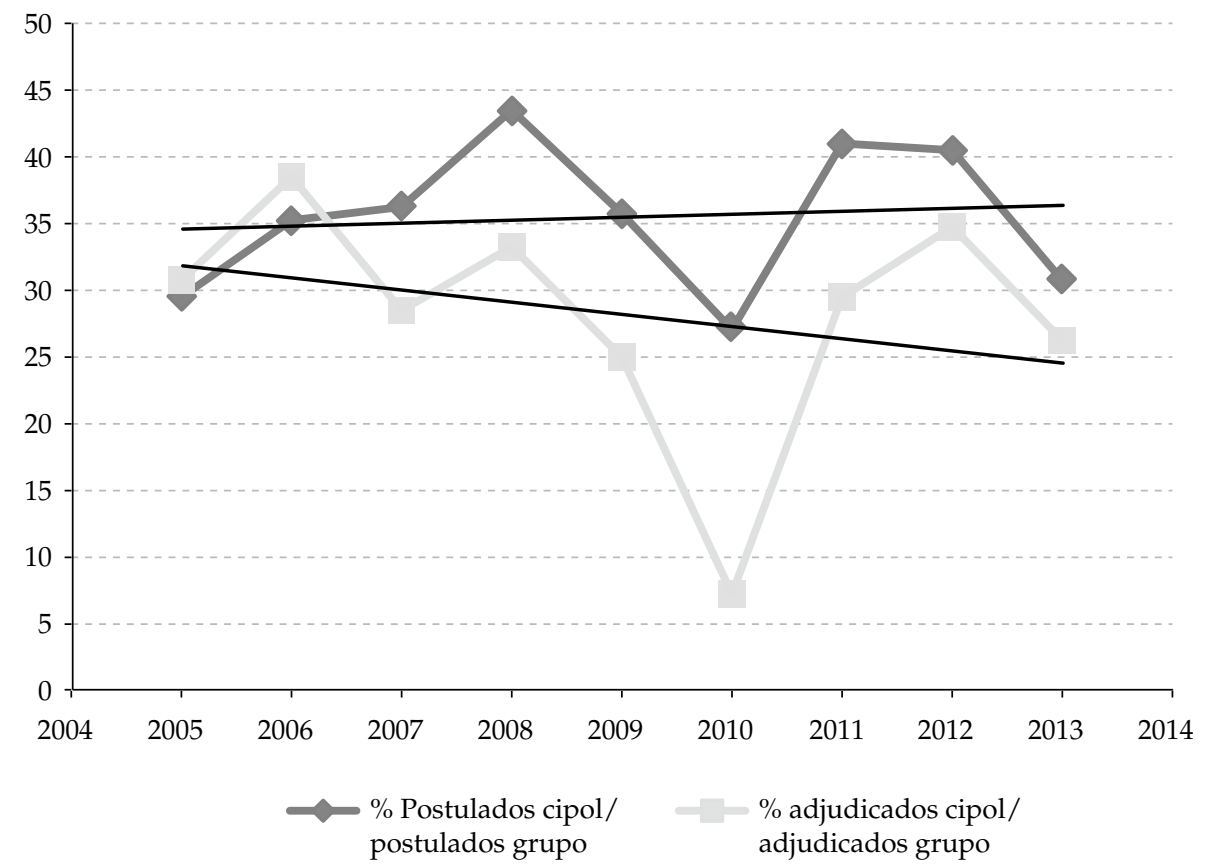

El Gráfico 5 muestra los PFR adjudicados entre 2005 y 2013 por género. Se observa que de un total de 43 proyectos, 35 (81\%) tiene a un hombre como investigador principal, mientras que solo ocho (19\%) corresponde a mujeres. De esos ocho proyectos, hay tres que corresponden a una misma investigadora, lo que significa que solo seis mujeres han obtenido PFR desde el año 2005. Cabe resaltar que la participación de las mujeres se concentra en años recientes. La situación es diferente con los PFI (Gráfico 6) donde de un total de once proyectos, seis son de académicas. Aquí también la participación femenina aumenta los últimos años para los que hay datos: entre 2010 y 2012, las mujeres obtienen seis de los ocho PFI adjudicados. Los datos parecen apuntar a un progresivo aumento de las investigadoras, especialmente mediante PFI, en relación con el claro predominio de los investigadores hombres en los PFR.

Esto quiere decir que la participación femenina en adjudicación de PFR de la disciplina se mantiene constante desde 1991 en torno al 20\%. Recién en 1998 una mujer ganó por primera vez uno de estos fondos, pasando a constituir el $20 \%$ de los adjudicados ese año. En 2003, 2004 y 2005, investigadoras obtuvieron el 50\%, con 1, 2 y 1 proyectos respectivamente. En total, desde 1991 a 2005 Fernández reporta un total de 44 PFR en ciencia política de los que ocho $(18 \%)$ pertenecen a cinco mujeres investigadoras (Fernández, 2006: 268). 
Gráfico 5. PFR adjudicados por género.

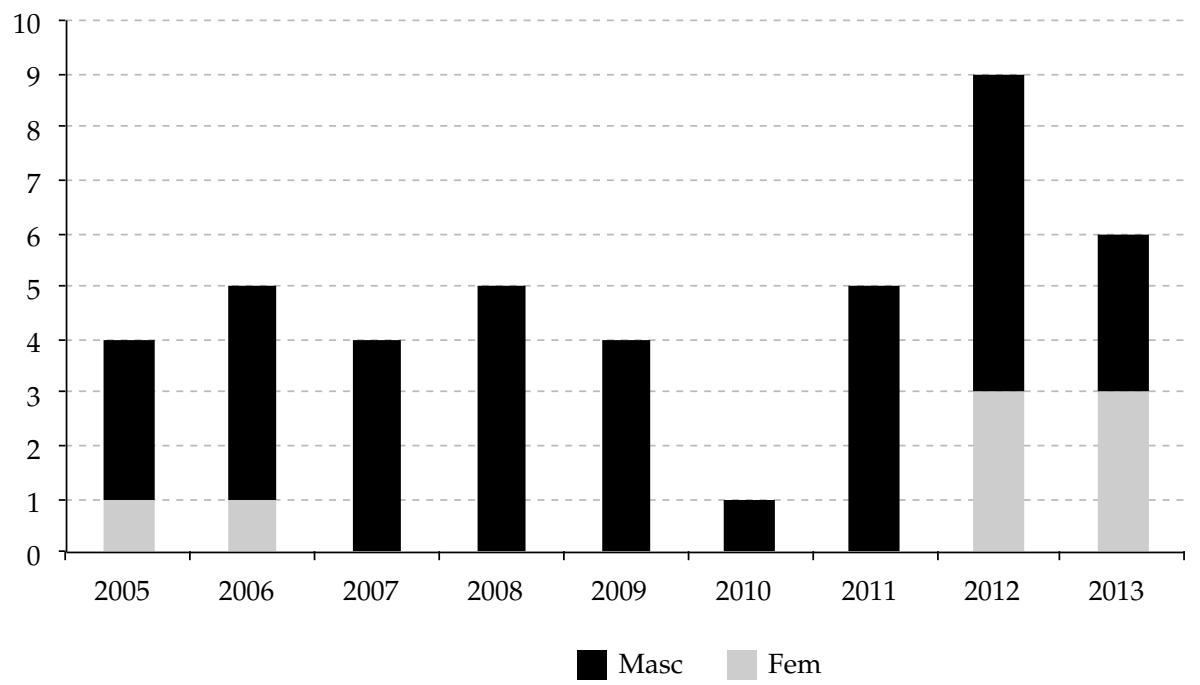

Gráfico 6. PFI adjudicados por género.

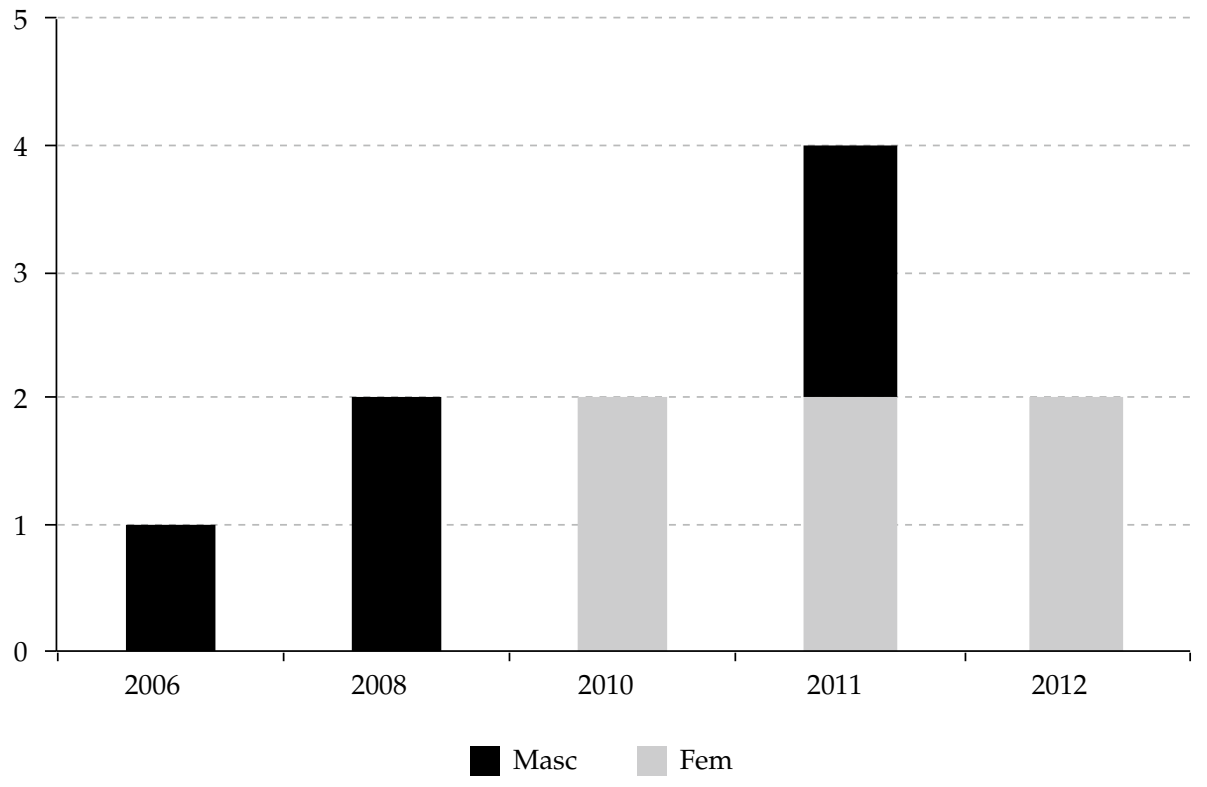

Si bien es cierto que ganar un proyecto aumenta sustancialmente las probabilidades de obtener otros con posterioridad, la repetición de nombres no parece describir un sistema impenetrable y más bien la existencia de un investigador con cinco proyectos sobresale como una anomalía. Desde 2005, con los datos disponibles y considerando Regulares, Iniciación, Cooperación Internacional y posdoctorado, se han aprobado 59 proyectos 
FONDECYT en ciencia política y relaciones internacionales. De ellos, 25 corresponden a investigadores que han ganado un único proyecto. Trece investigadores figuran con más de un proyecto, los que se distribuyen de la siguiente manera: Siete investigadores han ganado dos proyectos, cinco investigadores han obtenido tres proyectos y un investigador acumula cinco proyectos.

Por último, el Gráfico 7 muestra los 59 proyectos FONDECYT adjudicados entre 2005 y 2013 según la institución patrocinante. Las instituciones que concentran la mayor cantidad de proyectos en este periodo son la Universidad de Chile (15), PUC (15) y UDP (11).

\section{REVISTAS CHILENAS}

La relevancia de las revistas académicas, especialmente aquellas que pertenecen a índices como ISI Web of Science, Scopus o Scielo ha ido en aumento en América Latina (Buquet, 2013). Basado en cifras de Latindex, Barrientos (2013: 123) señala que las revistas chilenas de ciencia política y "disciplinas afines" corresponden a alrededor del 15\% de las 102 revistas indexadas en América Latina, el mayor número después de las mexicanas $(25 \%)$ y brasileñas $(20 \%)$.

Publicar en revistas indexadas permite difundir de manera amplia y eficiente el conocimiento especializado. Para pertenecer a estos registros, las revistas deben cumplir con estándares como referato doble ciego, periodicidad y constancia de publicación, entre otras (Barrientos, 2012: 122). Una vez que acceden, logran mayores niveles de visibilidad, mejorando su impacto (Buquet, 2013). Sin embargo, muchas bibliotecas universitarias

Gráfico 7. Proyectos FONDECYT adjudicados 2010-2013 por institución

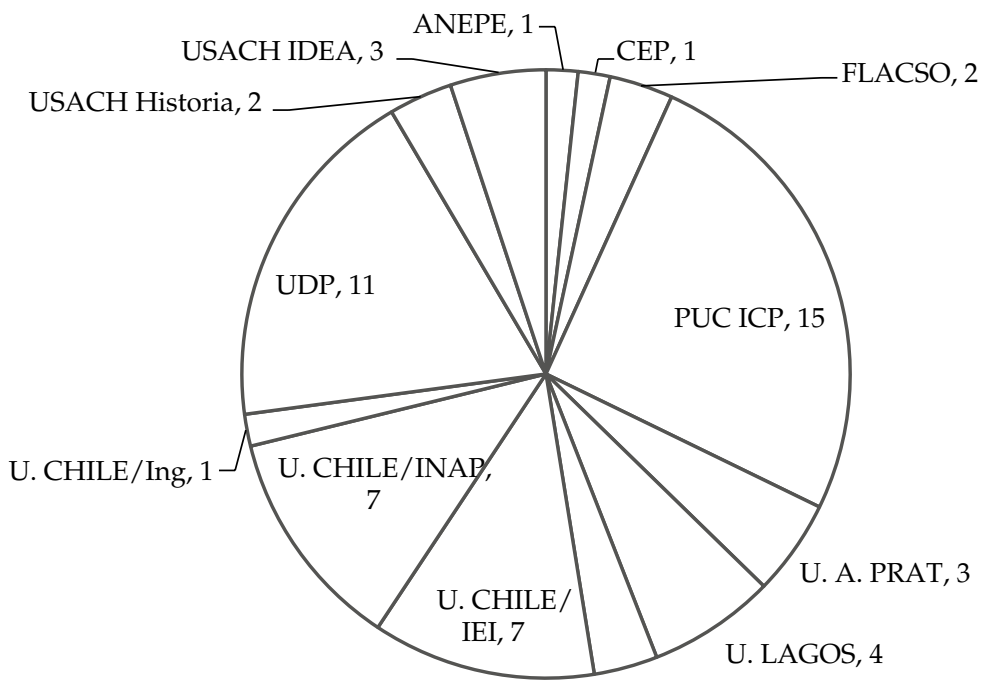

U. A.H., 2 
en Chile ofrecen un acceso limitado a las caras bases de datos de mayor prestigio, lo que dificulta la incorporación masiva de la academia nacional a estas influyentes redes de conocimiento.

Al 2015 existen 13 revistas de la disciplina y afines, algunas vinculadas a universidades y otras a centros de investigación o de pensamiento (Tabla 5). Todas ellas tienen referato doble ciego e informan en sus sitios web su nivel de indexación. Sin embargo, solo RCP pertenece a ISI, un índice frecuentemente exigido por el principal financiador de proyectos individuales del país, FONDECYT, para publicar los resultados de investigaciones. Cuatro revistas están en Scielo y muchas más en Latindex y otros.

La progresiva indexación de revistas latinoamericanas podría contribuir al impacto de investigaciones locales en la disciplina, contra las críticas de parroquialismo. Sin embargo, la internacionalización aún está lejos. Buquet 2013 señala con pesimismo que el creciente número de revistas de ciencias sociales que existe en nuestra región ha sido destinado a canalizar la producción de sus propios investigadores, lo que busca cumplir con exigencias de evaluación, pero no logra visibilidad ni impacto.

Existe un esfuerzo considerable y relativamente reciente de las revistas chilenas de ciencia política por cumplir con los requerimientos señalados. Solo las más nuevas surgieron con estos criterios. Las más antiguas, en cambio, fueron en sus orígenes vías de difusión del trabajo realizado en las instituciones que las crearon. Por eso, todavía algunos editores deben esforzarse por enfrentar presiones de los miembros de sus departamentos para evitar la endogeneidad de sus publicaciones. También tienen dificultad para hallar revisores anónimos apropiados, un trabajo ad honorem que tiene creciente demanda y que los académicos no siempre ven como un deber hacia la comunidad disciplinar. ${ }^{12}$

\section{CONCLUSIONES}

Si la década pasada marcó un "boom" de la oferta de pregrado en ciencia política, los últimos diez años apuntan a la consolidación académica de la disciplina en Chile, reflejada en proyectos de investigación, publicaciones y la creación de los primeros doctorados propiamente disciplinares en el país.

Las dos universidades que muestran mayor productividad científica, PUC y UDP, son al mismo tiempo las únicas que han conseguido establecer programas en todos los niveles de pre y posgrado, con el surgimiento de doctorados disciplinares el 2007 y 2014 respectivamente. ${ }^{13}$ Son, asimismo, las que entregan mayor información pública sobre las condiciones de sus plantas y programas académicos por medio de sus sitios web. 


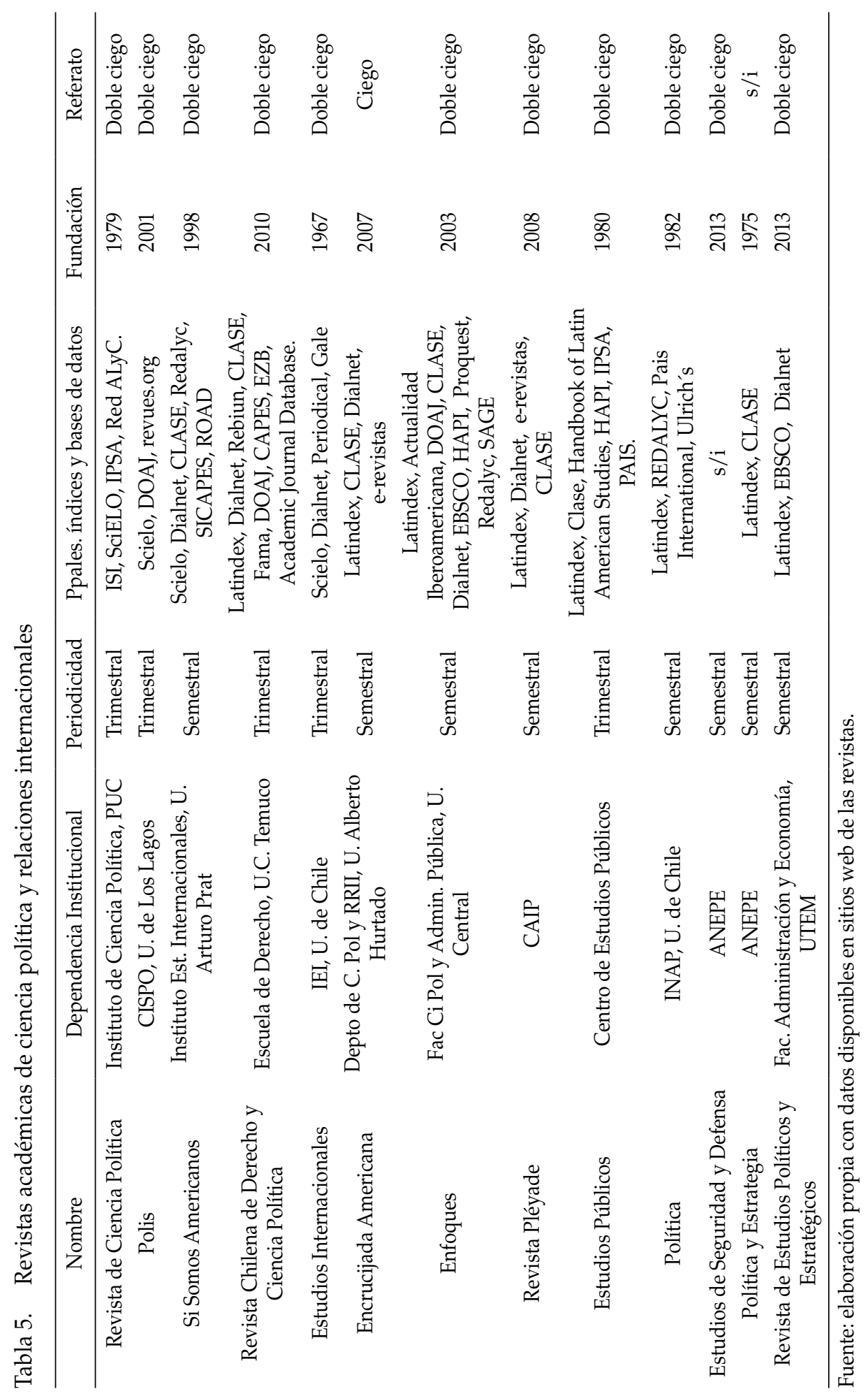


A pesar de los avances en autonomía disciplinar, varias universidades mantienen una estrecha vinculación con otras áreas de estudio, como se observa en su dependencia institucional y plantas docentes. La oferta de pregrado se ha mantenido relativamente estable, con tres carreras nuevas: USACH y UAH (2007) y UCT (2008) y dos desaparecidas: UTEM y Universidad de las Américas. Los programas de magíster son 10, incluido uno nuevo de la UDP (2013).

Persiste la poca transparencia pública respecto del tipo de adscripción de las y los docentes a los programas de pre y posgrado, lo que plantea un desafío importante con miras a permitir que futuros estudiantes tengan la información necesaria al momento de postular. Aquellos programas con más profesores externos suelen repetir nombres, debido a que sus docentes hacen clases en varias universidades. La composición de género de la planta académica no muestra una variación sustantiva; el promedio se mantiene levemente sobre el 20\%, aunque la mayor parte de los programas tiene alrededor de un tercio de académicas. Hay dos programas que cuentan con solo una mujer cada uno.

La mayor parte de las publicaciones informadas en los sitios web de los programas académicos son artículos de revistas especializadas, seguido por capítulos de libro y libros. La institución que acumula la mayor cantidad de artículos ISI desde 2010 es la PUC (36), seguida de la UDP (34). Bastante más atrás se encuentran UDD (9), Universidad de Chile (9 entre INAP e IEI) y UAH (4). Por otro lado, la UDP supera a las otras instituciones en volumen total de publicaciones: 110 entre 2010 y 2014.

Los concursos FONDECYT Regular e Iniciación son la principal fuente de financiamiento de proyectos individuales de investigación, los que compiten con proyectos de otras 14 subáreas del Derecho en el grupo "Ciencias jurídicas, estudios internacionales y ciencia política". Un análisis de los proyectos postulados y adjudicados desde 2005 muestra que mientras más proyectos postulan, más son adjudicados. A partir de 2011 se observa un incremento de los proyectos adjudicados tanto de la disciplina como del grupo.

En contra de una creencia difundida, la postulación de Regulares en la disciplina no ha aumentado en forma significativa en la última década; sí han aumentado, en cambio, los Iniciación. Eso significa que deberíamos esperar un incremento de postulaciones a Regulares en el futuro, puesto que solo se puede concursar en Iniciación una vez, al comienzo de la carrera.

Mientras la ciencia política aporta sistemáticamente una parte más grande del total de proyectos postulados que el promedio del grupo, casi todos los años se adjudica alrededor de 10\% menos que el promedio. Alrededor de 20\% de los Regulares adjudicados desde 2005 en la disciplina tiene a una mujer como investigadora principal. La cifra muestra continuidad con la década anterior. Si hay alguna razón de optimismo respecto de avanzar hacia la paridad, ella se encuentra en los Iniciación, donde los últimos años muestran un aumento significativo de las investigadoras. Las instituciones patrocinantes que concentran la mayor cantidad de proyectos FONDECYT desde 2005 son la Universidad de Chile (15), PUC (15) y UDP (11).

Por último, se verifica un avance hacia la indexación de las 13 revistas de la disciplina. Cuatro son ya Scielo y una ISI. 
Estos desarrollos apuntan a una estabilización de la oferta de pregrado y un importante desarrollo de la investigación y las publicaciones. El surgimiento de los primeros doctorados y la indexación de varias revistas nacionales podrían contribuir a dejar el excesivo énfasis en docencia que marcó el "boom" de comienzos del milenio y a recuperar un debate intelectual como el que vio nacer a la disciplina en los años 60. Está por verse si los avances en la oferta de programas académicos, proyectos de investigación y publicaciones quedarán circunscritos a unas pocas universidades donde la disciplina ya parece consolidada o se extenderá este fenómeno hacia otras instituciones, incluidas las de regiones. El fortalecimiento de la Asociación Chilena de Ciencia Política podría ayudar a una consolidación más amplia y plural de la ciencia política en el país.

\section{REFERENCIAS}

Altman, David. 2005. "La institucionalización de la ciencia política en Chile y América Latina: una mirada desde el sur". Revista de Ciencia Política 25 (1): 3-15.

Altman, David. 2012. "Where is Knowledge Generated? On the Productivity and Impact of Political Science Departments in Latin America". European Political Science 11: 71-87.

Barrientos del Monte, Fernando. 2013. "La Ciencia Política en América Latina. Una breve introducción histórica". Convergencia. Revista de Ciencias Sociales 20 (61): 105-133.

Buquet, Daniel. 2013. "Producción e impacto de las ciencias sociales en América Latina". Documento de Trabajo. Buenos Aires: CLACSO.

Fernández, María de los Ángeles. 2005. "Ciencia política en Chile: un espejo intelectual”. Revista de Ciencia Política 25 (1): 56-75.

Fernández, María de los Ángeles. 2006. "Mujer y ciencia política en Chile: ¿algo nuevo bajo el sol?". Política (46): 261-289.

Freidenberg, Flavia y Andrés Malamud. 2013. “Politólogos on the Run: Contrasting Paths to Internationalization of Southern Cone Political Scientists." Latin American Politics and Society 55 (1): 1-21.

Fuentes, Claudio y Graciela Santana. 2005. "El 'boom' de la ciencia política en Chile: escuelas, mercado y tendencias". Revista de Ciencia Política 25 (1): 16-39.

Garretón, Manuel Antonio. 2005. "Social sciences and society in Chile: institutionalization, breakdown and rebirth". Social Science Information 44: 359-409.

Huneeus, Carlos. 2006. "El lento y tardío desarrollo de la ciencia política en América Latina, 1966-2006". Estudios Internacionales 155: 137-156.

Matus, Nicolás. 2014. 30 Años de la Asociación Chilena de Ciencia Política. Documento distribuido por la Asociación Chilena de Ciencia Política en el XI Congreso Chileno de Ciencia Política, Universidad Alberto Hurtado, Santiago.

Navarrete, Bernardo, Mauricio Morales y Pedro Figueroa. 2005. “La ciencia política en Chile y el estado de su docencia". Estudios Sociales 116 (2): 25-52.

Nohlen, Dieter. 2006. "La ciencia política en América Latina", en Diccionario de Ciencia Política, tomo I, editado por D. Nohlen, 171-176. México: Porrúa/El Colegio de Veracruz.

Rehren, Alfredo y Marco Fernández. 2005. “La evolución de la ciencia política en Chile: un análisis exploratorio (1980-2000)". Revista de Ciencia Política 25 (1): 40-55.

Viacava, José. 2012. "La Ciencia Política en Chile: una carrera en expansión y transformación". Política 50 (1): 93-110.

www.conicyt.cl 
Claudia Heiss es doctora en ciencia política por la New School for Social Research, es profesora asistente del Instituto de Asuntos Públicos de la Universidad de Chile e investigadora asociada del Centro para la Conflictividad y Cohesión Social COES. Ha publicado, entre otros, en la revista Latin American Politics and Society. Actualmente investiga sobre los estados de excepción y el constitucionalismo latinoamericano.

E-mail: cheiss@iap.uchile.cl. 